\title{
Incommensurability and Cross-Language Communication
}

Xinli Wang, Juniata College

Ashgate New Critical Thinking in Philosophy

A dominant epistemological assumption behind Western philosophy is that it is possible to locate some form of commonality between languages, traditions, or cultures—such as a common language or lexicon, or a common notion of rationality — which makes full linguistic communication between them always attainable. Xinli Wang argues that the thesis of incommensurability challenges this assumption by exploring why and how linguistic communication between two conceptually disparate languages, traditions, or cultures is often problematic and even unattainable. According to Wang's presuppositional interpretation of incommensurability, the real secret of incommensurability lies in the ontological set-ups of two competing presuppositional languages.

This book provides many original contributions to the discussion of incommensurability and related issues in philosophy and offers valuable insights to scholars in other fields, such as anthropology, communication, linguistics, scientific education and cultural studies.

Contents: The many facets of incommensurability; Incommensurability as untranslatability; Incommensurability and conceptual schemes; In defense of the very notion of conceptual schemes; Case studies: the emergence of truth-value gaps; Toward the presuppositional interpretation; Kuhn's taxonomic incommensurability: a reconstruction; A defense of the notion of semantic presupposition; The structure of a presuppositional language; Existential presumptions and universal principles; Categorical frameworks; The failure of cross-language understanding; Hermeneutic understanding in abnormal discourse; Informative communication breakdown: the transmission model; Dialogical communication breakdown I: Gadamer's conversation model; Dialogical communication breakdown II: Habermas's discourse model; The concept of incommensurability; Bibliography; Index.
Unique Selling Points:

- Presents and defends a notion of presuppositional languages, which provides a genuine alternative interpretation to the traditional notion of conceptual schemes.

- New interpretation of incommensurability presented—fills a gap in the literature with its original approach.

April 2007384 pages

Hardback 978-0-7546-3034-0 \$99.95

All online orders at www.ashgate.com receive a discount.

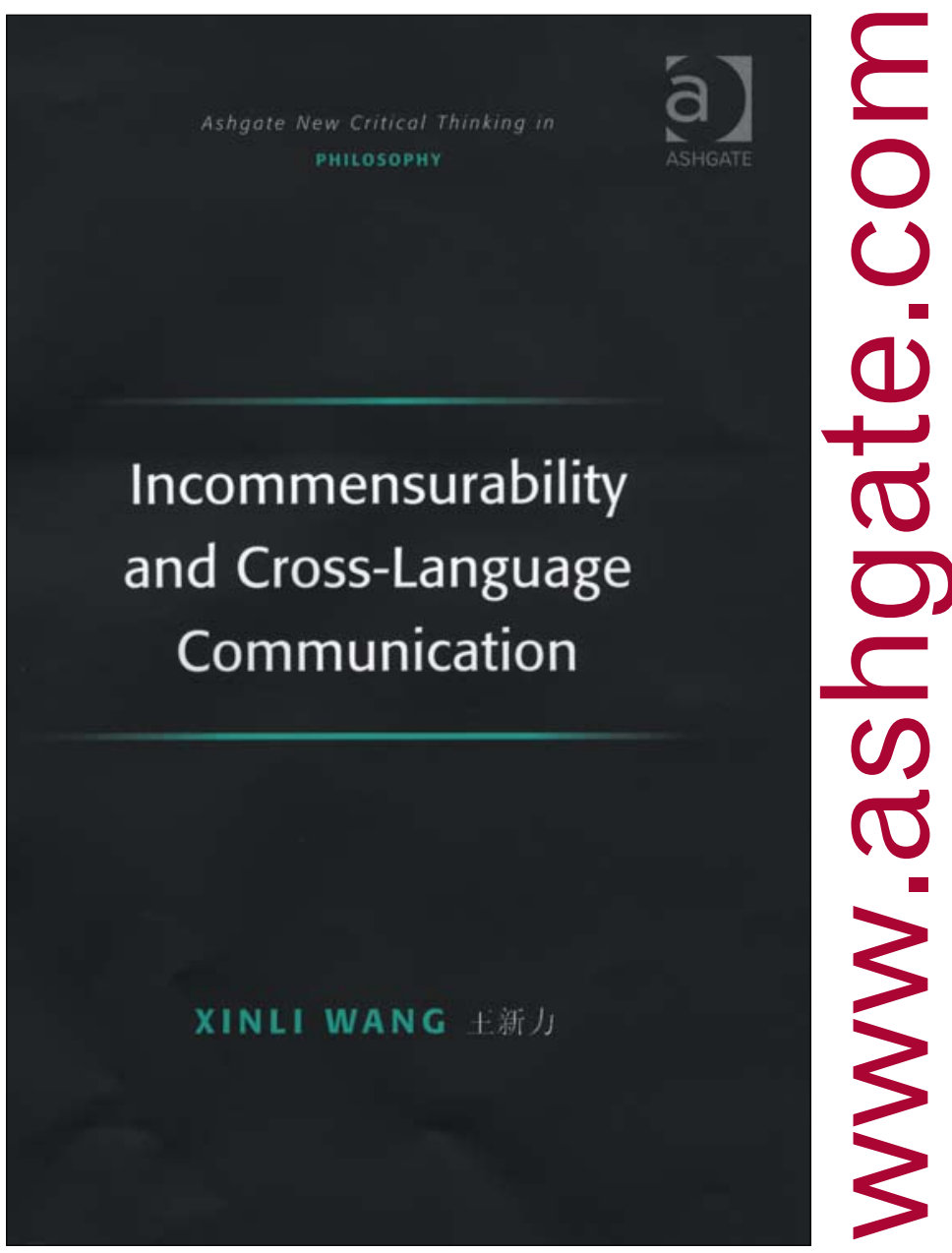

Please visit www.ashgate.com for sample pages

\section{ASHGATE}

40 years of independent publishing
Ashgate Publishing $\mathrm{PO}$ Box 2225

Williston VT 05495-2225 USA Toll-free: 800-535-9544 Email: orders@ashgate.com Web: www.ashgate.com 